\title{
Healthcare financing in Russia: mechanism and assessment of regional budget opportunities
}

\author{
Tatyana $V$. Faiberg ${ }^{1, *}$, and Irina $N$. Shcherbakova ${ }^{1}$ \\ ${ }^{1}$ Baikal State University, 11, Lenin str., Irkutsk, Russia
}

\begin{abstract}
In the difficult economic conditions in Russia, caused, as in the all countries, by the consequences of the coronavirus pandemic, the search for additional government revenues is becoming especially relevant. All possibilities of cutting budget expenditures are being considered, including the optimization of the number of civil servants. The deputies of the State Duma of the Russia over the past month have been actively discussing the effectiveness of the functioning of state extra-budgetary funds and expressing ideas about the abolition of the Pension Fund of Russia and others, with the simultaneous return of functions back to the federal budget. It is important to reasonably assess the effectiveness of the financial mechanism of each extra-budgetary fund in Russia, including the Federal and Territorial Compulsory Medical Insurance Funds. To this end, it is necessary to comprehensively consider the mechanism of financing health care in the country within the framework of the current budget-insurance model. This article reveals the features of the financial mechanism in the healthcare sector in Russia, primarily in terms of methods for the formation of financial resources. In general, the Russian health care system is financed by the country's budgets, Compulsory Medical Insurance Funds, voluntary medical insurance and paid medical services. In accordance with this, the budget, insurance and market methods for the formation of financial resources in health care are identified. The article describes each method; the effectiveness of the current financial mechanism was assessed and recommendations for its improvement were proposed.
\end{abstract}

Keywords: Health, financing, budget expenditures on healthcare, financial mechanism

\section{Introduction}

In the context of the coronavirus pandemic, all countries began to pay special attention to such economic sector as healthcare. The current epidemiological situation exacerbates the issue of the effectiveness of the health care system, the quality of medical care. Each resident involuntarily compares the availability of medical services in different countries, which directly depends on the chosen funding model and on the well-functioning financial mechanism in the healthcare sector. All this determines the relevance of the organization of financing of medical institutions and development prospects in this area.

\section{Problem Statement}

In Russia, the healthcare financing process has many shortcomings in the financing mechanism for medical institutions. In particular, these include the existence of redundant links in the chain of the process of transferring funds to medical institutions, which affects the final amount of funding for medical services; the complexity of bringing funds to institutions; the availability of different ways of obtaining and using financial resources by medical organizations. In this regard, it is necessary to analyze the organization of the financial mechanism in the Russian healthcare system and determine the ways to improve it.

\section{Research Questions}

The research analyzed the practice, studied and systematized the scientific literature on the financing mechanism of economic sectors and, in particular, the healthcare system in Russia.

\subsection{Content of the «financing mechanism»}

In Russian practice, the content of the «financing mechanism» is considered both from a broad and narrow point of view.

In a broad point of view, the financing mechanism is identified with the concept of «financial mechanism» developed in Russian financial science. This is «a set of types and forms of organization of financial relations, specific methods for the formation and use of financial resources and methods of their quantitative determination» $[5,7]$. This concept was first formulated in the 70 s of the twentieth century in the papers of M.A. Pessel in relation to corporate finance [6]. In the papers of V.P. Ivanitsky [3] V.I. Samarukha [8], the

* Corresponding author: faibergtv@mail.ru 
financial mechanism was considered in relation to sectors of the economy. In our opinion, this concept applies to other areas of finance, in particular, healthcare.

Further, Yu. M. Berezkin has offered financialengineering interpretation of the concept of «financial mechanism» [2].

For the purposes of this study, the financing mechanism will be considered from a broad perspective as synonymous with the financial mechanism: a financial mechanism refers to the way in which a business, organization, or program receives the funding necessary for it to remain operational [11].

From a narrow point of view, the financing mechanism is the transfer of funds to enterprises, institutions, and the population.

\subsection{Features of the Russian healthcare financing mechanism}

The papers of such Russian economists as O.V. Emelyanova, N.V. Krivenko, E.S. Malysheva, I. Sheiman, S. Terentyeva, A.I. Tsvetkov, N.I. Yashina, K.S. Yashin and others are devoted to the problems of healthcare financing, assessing the effectiveness and comparing models of healthcare financing.

Most studies focus on particular issues of organizing healthcare financing in Russia, the most relevant of which are assessing the effectiveness of healthcare financing models $[4,10,12]$, features of health care financing at the federal level [1, 13] and in the regions [9].

From our point of view, the issue of simplifying the financing mechanism for medical services (possibly by reducing the «intermediate links») in order to increase the availability of medical care, to rapidly increase the volume of medical services in a pandemic, that is, to increase maneuverability, while improving the quality of medical services is of principle.

\section{Purpose of the Study}

The purpose of the study is to highlight the peculiarities of the Russian healthcare financing mechanism, primarily in the methods of generating financial resources, to assess the effectiveness of the current mechanism, and to develop recommendations for its improvement.

\section{Research Methods}

The depth of research, the validity of scientific results, the reliability of conclusions and recommendations were ensured by the use of general scientific methods: observation, comparison, synthesis of theoretical and practical material, using methods of economic and statistical analysis (grouping, comparison, generalization).

\section{Findings}

The financing mechanism in healthcare in Russia is quite complex. It has developed as a result of reforms not only in the healthcare sector, but also as a result of budget reforms (introduction of performance-based budgeting; Treasury budget execution; procurement systems; changes in the organizational and legal forms of state (municipal) institutions, etc.), focused primarily on borrowing foreign experience, the so-called «best practice».

Of all the elements of the financial mechanism, the methods of forming financial resources, methods of their transfer and quantification have significant features in healthcare.

The basis of the financial mechanism in health care is the financial relationship between recipients of medical services and medical organizations in the process of redistribution of financial resources that mediate the provision of medical care (Figure 1).

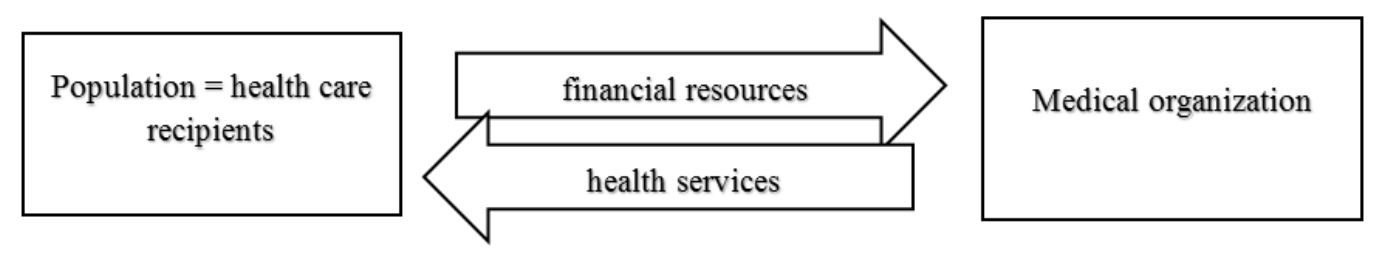

Figure 1. Healthcare Financial Relationship Diagram

In world practice, there are different methods of transfer of financial resources depending on the chosen model of financing of health care: budget model, insurance model or budget-insurance model.

In Russia, a budget-insurance model of financing health care has developed, despite attempts to implement an insurance model. In my opinion, in Russia there is a «quasi-budget-insurance» model, or rather a budget model financing of health care, because it historically developed in the early twentieth century and proved its effectiveness. Before 1917, there was no public health care system in Russia practically and private medical practice dominated. Therefore, attempts to complicate the existing mechanism of financing healthcare institutions and to introduce insurance reduce the efficiency of financial resources and the availability of medical services.

The analysis of the financing mechanism of the state healthcare system in Russia makes it possible to identify the following methods of generating financial resources, depending on funding sources:

- market method (method of exchange relations);

- actually financial (budgetary) method;

- insurance. 
In Russia, the market method arose in the 90s of the twentieth century and means direct transfer of money to medical institutions as payment for medical services. At the same time, medical services can be provided not only by public, but also by private organizations.
The budgetary method of generating financial resources in healthcare involves the redistribution of funds received from taxes into the country's budget system in favor of medical institutions under the Program of State Guarantees of Free Medical Care (Figure 2).

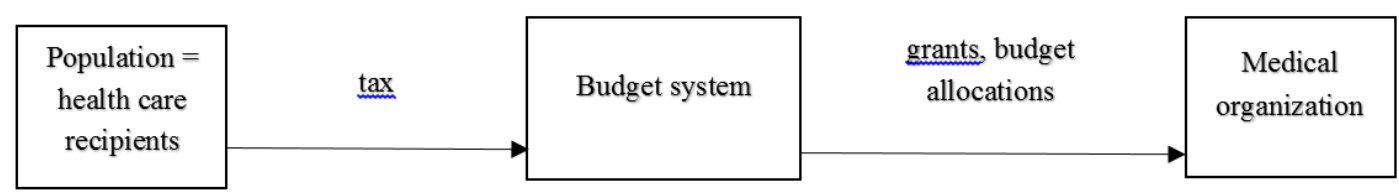

Figure 2. Budgetary method of financial resources formation in Russian healthcare

Budgets of all levels of budget system participate in the process of budget financing of institutions: Federal, regional and local budgets. The main role is assigned to regional budgets, since almost all health institutions in the country are regional owned.

The form of transferring funds to medical institutions may vary depending on the legal form of the institution. State budgetary and autonomous institutions receive grants (for the fulfillment of a state assignment; for budget investments; for other purposes), and government - budget allocations. At the same time, budgetary and autonomous institutions have freedom in the disposal of income from paid services, while government institutions irrevocably transfer them to the budget.

The insurance method of generating financial resources in the healthcare of Russia involves the compulsory and voluntary medical insurance.

Extra-budgetary Compulsory Health Insurance Funds were created in 1993 in Russia. This is the only system of extra-budgetary funds in Russia that has a two-level structure: the Federal Compulsory Health Insurance Fund and the Territorial Compulsory Health Insurance Funds in the regions of the Russian Federation (Figure 3).

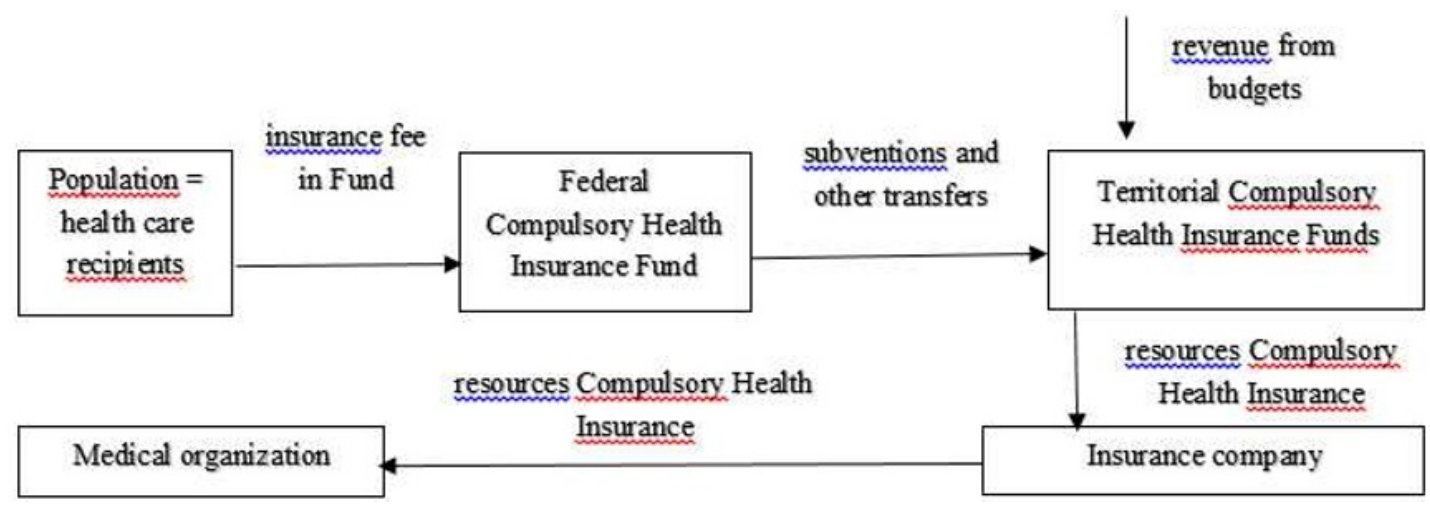

Figure 3. Insurance method of financial resources formation with compulsory medical insurance in Russia

The borrowed foreign experience of insurance medicine, aimed at improving the quality of medical services, and explaining the emergence of insurance companies in the mechanism of financing health care, did not radically change the medical care system, but increased the costs of maintaining funds, insurance companies, created new problems, negatively affected the availability of medical care.

The amount of funding for medical institutions depends on the number of services provided and the per capita financing rate, which, according to the law, should take into account all the costs of medical care. However, in fact, in the face of a constant budget deficit, it is not possible to finance all expenses, as in any other branch of the social sphere. Therefore, in practice, the financing rate is calculated taking into account the real capabilities of the budget, that is, not «from needs» but «from opportunities». In these conditions, the costs of maintaining funds and insurance companies only exacerbate the shortage of funds.
The costs of maintaining the Compulsory Health Insurance Funds in 2019 amounted to 15.19 billion rubles.

Insurance companies keep a percentage of the total cash flow for doing business, the amount of which is fixed annually by the laws of the regions «Budget of the Territorial Compulsory Health Insurance Fund». In each region, this percentage is different. For example, in the Irkutsk region in 2019, it amounted to $1 \%$. At the same time, the total cash flow from the Territorial Funds in 2019 amounted to 2265.98 billion rubles. Thus, according to the most modest estimates, insurance companies formed income only due to budget cash flow in the amount of 22 billion rubles, not counting fines and sanctions imposed on medical institutions for poorquality, untimely and/or incomplete medical care received by insurance companies ( 44.5 billion rubles were transferred fines in 2017).

It seems doubtful to integrate private insurance companies in the financial mechanism of the Russian 
state health system, which are aimed at making a profit, as a controller of the quality of medical services. Our conclusions are indirectly confirmed by the opacity of the statements of insurance companies on compulsory health insurance. In our opinion, not the desire to develop the voluntary health insurance sector by these companies is associated with receiving cash flow for compulsory health insurance.
The insurance method for the formation of financial resources with voluntary medical insurance in Russia is schematically shown in Figure 4.

This method of generating financial resources depends on the efforts of insurance companies to conclude insurance contracts for voluntary medical insurance, the established amount of insurance premiums and made insurance payments to medical organizations.

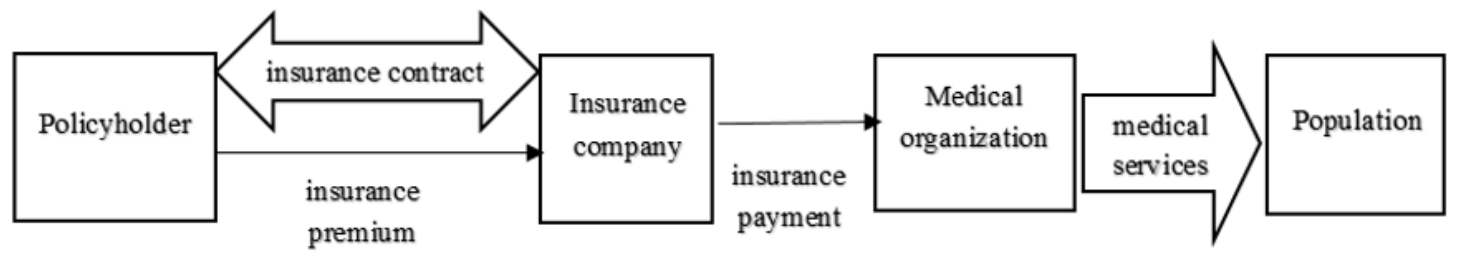

Figure 4. Insurance method of financial resources formation with voluntary medical insurance in Russia

According to the Bank of Russia, the volume of the voluntary medical insurance market in terms of the amount of contracts concluded in 2019 amounted to 136.1 trillion rubles. However, the volume of insurance payments is only 126.5 billion rubles with paid contributions of 180.65 billion rubles. Thus, the net income of insurance companies on voluntary medical insurance amounted to 54 billion rubles.

Thus, $1 / 3$ of the cash flow by the insurance method of generating financial resources from insurance companies in Russia is provided by compulsory medical insurance, while the costs of attracting customers are minimal.

The analysis of the insurance method in the healthcare financing mechanism of Russia showed a focus not on the development of the country's health care system, not on improving the quality of medical services, but on diversifying the Russian economy at the expense of insurance companies, whose stability in crisis is guaranteed by constant cash flow from extra-budgetary funds. From our position, insurance companies should actively develop voluntary medical insurance, and not claim a share in the cash flow of compulsory medical insurance.

Methods of using financial resources in health care depend more on the legal form of medical institutions; the participation of the Federal Treasury in financing the institutions; the applied procurement system than on the sources of their funding.

The ratio of healthcare financing sources in Russia is clearly shown in Figure 5.

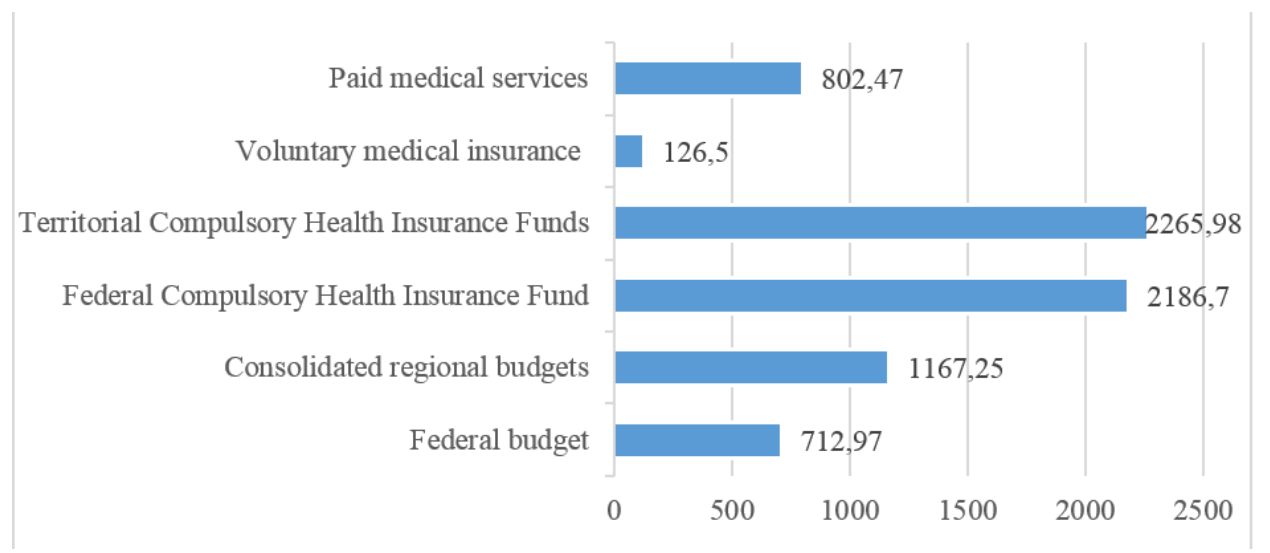

Figure 5. Sources of healthcare financing in Russia in 2019, billion rubles

Figure 05 clearly shows that the dominant cash flow passes through the compulsory health insurance funds (61\%). At the same time, a fairly high share of the Russian budgetary system in health care financing remains $(26 \%)$. Analyzing the structure of budget financing for healthcare, we can conclude that the regional budgets dominate, through which 1.163 .36 billion rubles were transferred in 2019 (62\% from all budgets).

It should be noted that despite the introduction of single-channel funding in the compulsory health insurance mechanism, still not all expenses of medical institutions for the provision of medical care under the «Program of State Guarantees of Free Medical Care» are covered by the funds of compulsory medical insurance funds. For example, costs of diagnosing and treating coronavirus infection. The problems associated with financing the procurement of equipment and medical supplies for coronavirus infection were resolved not through health insurance, but through budget funding (by the providing grants for other purposes). 
Thus, it is impossible in the system of compulsory health insurance to quickly increase the volume of medical care and, accordingly, financing without losing interest to insurance companies.

In this regard, we consider it expedient and economically justified to return to budgetary financing of healthcare in Russia with the transfer of most of the spending powers to the regions of the Russian Federation. They have the majority of medical organizations under their control and can quickly reallocate scarce resources within budgets according to financial policy priorities.

\section{Conclusion}

In the article, we identified the features of the financial mechanism in the healthcare sector in Russia, primarily in terms of methods for the formation of financial resources. The characteristics of the market, insurance and budgetary methods are given; the effectiveness of the current mechanism is evaluated and recommendations for its improvement are offered.

The main recommendations may be the transition to budgetary financing of healthcare in Russia; simplification of the insurance mechanism of compulsory health insurance by optimizing cash flows between Federal and Territorial Compulsory Health Insurance Funds, as well as between Territorial funds and insurance companies. Insurance companies should develop voluntary health insurance, and not apply for a percentage of the compulsory insurance health cash flow. The current situation - the coronavirus pandemic presents broad opportunities for the development of voluntary health insurance, subject to the development of quality insurance products. From our position, insurance companies, along with medical institutions, should be responsible for both timeliness and accessibility of medical care.

\section{References}

1. E.V. Ageeva. Financing of national systems health care: search of new approaches. Econ. and entrepren., 3(92), 1276-1281 (2018)

2. Yu.M. Berezkin. Two approaches to understanding the concept of financial mechanism: accountingfinancial and financial-engineering. Izv. of the Irkutsk State Econ. Acad., 2(82), 27-32 (2012)

3. V.P. Ivanitsky. Formation and development of a financial mechanism based on the distribution of monetary accumulations of industry (theory and methodology) (Irkutsk State University, Irkutsk, 1984)

4. N.V. Krivenko, A.I. Tsvetkov. Efficiency of Funding Healthcare for Ensuring the Economic Security of a Region. Econ. of the reg., 3, 970-986 (2018)

5. E.V. Markina. Finance. Textbook (KNORUS, Moscow, 2014)
6. M.A. Pessel. Financial and credit mechanism for intensifying public production (Finance, Moscow, 1977)

7. V.M. Rodionova. Finance. Textbook (Finance and statistics, Moscow, 1995)

8. V.I. Samarukha, N.S. Permyakova. Development of the financial mechanism of the corporation in conditions of risk and uncertainty (Baikal State Univ. of Econ. and Law, Irkutsk, 2001)

9. T.V. Shchyukina, S.N. Plyuta. Improvement of health care financing in the region. Univ. Bull., 5, 48-88 (2019)

10. I. Sheiman, S. Terentyeva. International Comparison of the Effectiveness of Budget and Insurance Models of Healthcare Financing. Econ. policy, 6, 171-193 (2015)

11. G. Wiesen. What is a Financial Mechanism? (2020). Retrieved from: https://www.wisegeek. com/whatis-a-financial-mechanism.htm.

12. N.I. Yashina, O.V. Emelyanova, E.S. Malysheva, N.N. Pronchatova-Rubtsova. A methodology methodology to evaluate the efficiency of public health financing in Russia. Finan. and credit, 3(771), 693-708 (2018)

13. N.I. Yashina, K.S. Yashin, E.S. Malysheva, O.I. Kashina, N.N. Pronchatova-Rubtsova. Features of state financing of health care in the context of economic reform (Publ. House of RADONEGE, Nizhny Novgorod, 2019) 